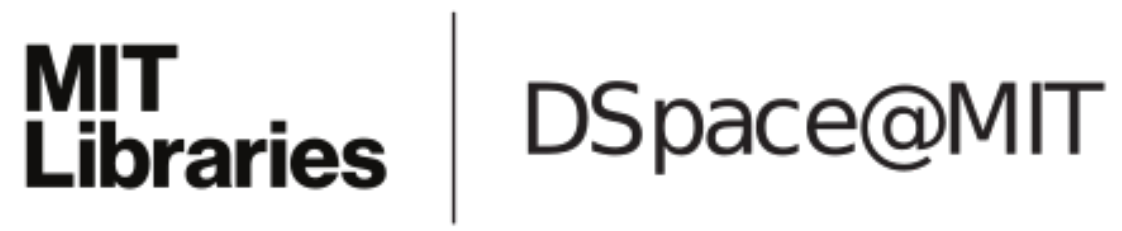

\author{
MIT Open Access Articles
}

Photo-Targeted Nanoparticles

The MIT Faculty has made this article openly available. Please share how this access benefits you. Your story matters.

Citation: Dvir, Tal et al. "Photo-Targeted Nanoparticles." 10, 1 (January 2010): 250-254 @ 2010 American Chemical Society

As Published: http://dx.doi.org/10.1021/n1903411s

Publisher: American Chemical Society (ACS)

Persistent URL: https://hdl.handle.net/1721.1/127167

Version: Author's final manuscript: final author's manuscript post peer review, without publisher's formatting or copy editing

Terms of Use: Article is made available in accordance with the publisher's policy and may be subject to US copyright law. Please refer to the publisher's site for terms of use. 


\title{
Photo-Targeted Nanoparticles
}

\author{
Tal Dvir ${ }^{\dagger} \ddagger$, Matthew R. Banghart $§$, Brian P. Timko $\ddagger, \|$, Robert Langer ${ }^{\dagger}$, and Daniel S. \\ Kohane ${ }^{*} \ddagger$ \\ † Department of Chemical Engineering, Massachusetts Institute of Technology, 45 Carleton Street, \\ Cambridge, Massachusetts 02142 \\ ₹ Laboratory for Biomaterials and Drug Delivery, Department of Anesthesiology, Division of Critical \\ Care Medicine, Children's Hospital Boston, Harvard Medical School, 300 Longwood Avenue, \\ Boston, Massachusetts 02115 \\ $\S$ Department of Neurobiology, Harvard Medical School, 220 Longwood Ave, Boston, \\ Massachusetts 02115 \\ " Harvard-Massachusetts Institute of Technology Division of Health Sciences and Technology, \\ Cambridge, MA 02139
}

\begin{abstract}
We report a novel and simple proof-of-concept of a nanoparticulate system that targets any tissue selectively upon illumination. Nanoparticles were covalently functionalized with the amino acid sequence YIGSR, which adheres to the $\beta 1$ integrins present on most cell surfaces. This peptide was masked with a caging group, rendering it biologically inert. Illumination with UV light released the caging group from the YIGSR, allowing binding to cells.
\end{abstract}

Targeting of drugs and drug delivery systems to diseased cells and tissues using nanoparticles has emerged as a central focus in drug delivery research, as it can minimize nonspecific toxicity and/or enhance the efficiency of therapy. Targeting of systemically-administered nanoparticles can be passive or active. Passive targeting depends on the physical properties of the particles and/or the target tissue to encourage relatively selective uptake. Example of this include the selective uptake of microparticles by phagocytic cells ${ }^{1}$, and the size-dependent accretion of nanoparticles within the relatively leaky vasculature of tumors ${ }^{2}$. However, since the majority of clinical conditions do not provide means of passive targeting, active targeting becomes necessary, in which the nanoparticles are delivered to their targets by specific ligands. Such ligands include antibodies, peptides or aptamers ${ }^{3}$, which bind specific receptors, channels or other molecules on the cell membrane ${ }^{4}$. Recent studies have demonstrated selective targeting of engineered nanoparticles to tumors ${ }^{5-7}$ and clinical feasibility of such systems has been demonstrated ${ }^{8}$. Unfortunately, that approach is limited by the relative paucity of known specific cell-surface ligands. This research addresses the urgent need for additional methods of targeting nanoparticles.

Recently, light has been used to release therapeutic agents from delivery systems or to activate cytotoxic drugs $9^{-} 11$. For example, liposomes have been made from lipids that change membrane permeability on exposure to near-UV light, releasing their contents ${ }^{9}$. Drug release has also been triggered by irradiating liposomes conjugated to hollow gold nanoshells with a near-infrared (NIR) pulsed laser ${ }^{12}$.

\footnotetext{
* To whom correspondence should be addressed, Daniel.Kohane@ childrens.harvard.edu.
} 
Here we describe the use of light to target nanoparticle binding (as compared to single release events) in specific illuminated areas. The basic design (Figure 1) is a drug-loaded nanoparticle whose surface is covalently modified with a targeting moiety consisting of an avid but nonspecific ligand that is rendered biologically non-functional ("caged") and prevented from binding by chemical modification with a photo-removable protecting group ${ }^{13}$. The caging group is removed at the desired site by illumination.

For proof of concept, we used commercially available carboxylated polystyrene nanoparticles with diameters of $328 \pm 2 \mathrm{~nm}$ (Figure S1 in Supporting Information) as model nanoparticles. The non-specific ligand was the peptide YIGSR - an amino acid sequence in laminin that is crucial for adhesion to integrin $\beta 1$ on the cell membrane ${ }^{14}$ of a broad range of potential target cell types including stromal and endothelial cells, which are present in all tissues (Figure 2A and $\mathrm{B}$, respectively).

The biological activity of YIGSR can be greatly attenuated by mutation or deletion of tyrosine 15,16 . We inferred that caging that tyrosine with 4,5-dimethoxy-2-nitrobenzyl (DMNB) (Figure 1), would inactivate the peptide until the cage was removed by illumination. DMNB was selected because of its established caging methodology and its documented rapid release from biologically-relevant substrates ${ }^{17,} 18$.

To verify that the caged peptide (GGGGY(DMNB)IGSR-NH ${ }_{2}$; the polyglycine sequence served as a spacer) could be un-caged, releasing the active peptide (GGGGYIGSR-NH $\mathrm{N}_{2}$ ), solutions of caged peptides $(1 \mathrm{mg} / \mathrm{mL})$ were subjected to 1 minute of illumination at $365 \mathrm{~nm}$ then evaluated by High Performance Liquid Chromatography with UV detection (HPLC-UV) at $210 \mathrm{~nm}$, and compared to solutions of caged peptide that were not illuminated, and of uncaged peptide. Retention time of the un-caged peptide in the HPLC column was $\sim 20$ minute (Figure 3a) while that of the un-illuminated caged peptide was longer ( 30 min, Figure $3 b$ ), presumably due to the hydrophobic caging group. One minute of illumination of the caged peptide caused a marked shift in the retention time toward that of the un-caged peptide (Figure $3 \mathrm{c})$, indicating rapid un-caging and activation of the peptide for cell binding.

The amine-terminated caged peptide/targeter was conjugated to the surface of carboxylterminated polystyrene nanoparticles using 1-ethyl-3-(3-dimethylaminopropyl) carbodiimide (EDC) and sulfo- $N$-hydroxysuccinimide (NHS) activation chemistry ${ }^{19}$. The nanoparticles with caged peptides $(200 \mu \mathrm{g} / \mathrm{mL})$ had a broad peak at $\sim 1100 \mathrm{~cm}^{-1}$ by FTIR, corresponding to the ether bond that links DMNB to YIGSR (Figure. 4a). Rapid un-caging was documented by progressive disappearance of the peak at $1100 \mathrm{~cm}^{-1}$ after illumination for 1 and 5 seconds (Figure 4a). Similarly, spectrophotometry at $405 \mathrm{~nm}$ (Figure 4b) showed rapid release of free DMNB from nanoparticles with caged peptides upon illumination.

To demonstrate that nanoparticles with caged ligands only adhere to cells after light activation, human umbilical vein endothelial cells (HUVECs) were cultured in $60 \mathrm{~mm}$ culture dishes for 24 hours. Then, the culture medium was replaced with medium containing caged nanoparticles $(200 \mu \mathrm{g} / \mathrm{mL})$ and the culture was illuminated for 1 minute (Figure 5a). Fifteen minutes later the dishes were washed and examined under a UV lamp. Nanoparticles (appear white) covered most of the culture dish area. In contrast, dishes treated in the same manner but without illumination showed few nanoparticles, mostly adhering at the edges. These results suggest light-dependent binding.

To provide a quantitative assessment of nanoparticle photo-targeting, HUVECs and mesenchymal stem cells (MSCs) were grown on culture slides for 24 hours then exposed to media containing $20 \mu \mathrm{g} / \mathrm{mL}$ fluorescent nanoparticles. The slides were illuminated for 1 minute, then after 30 minutes were washed, fixed and stained. The number of cells which were 
targeted by the nanoparticles was counted under microscopy and expressed as a percentage of total cells (Figure 5b). In both HUVECs and MSCs, the percentage of attachment of caged nanoparticles was significantly higher after 1 minute of illumination than in non-illuminated cultures. Furthermore, cell binding of illuminated caged nanoparticles was similar to that of particles conjugated to un-caged peptides; $p=0.67$ and 0.53 in HUVECs and MSCs, respectively. Binding of the non-illuminated caged nanoparticles cells was similar to that of nanoparticles whose surfaces were modified in the same manner with a non-adhering peptide (FHPDYRVI), confirming that the caging group inactivated the YIGSR (at least to the extent that it was as poor a ligand as the non-adhering sequence). The group with the non-adhering peptide was illuminated, so as to also rule out illumination as the cause of cell binding.

To demonstrate the ability of photo-targeting to provide spatial targeting of the caged particles, HUVECs incubated in the dark were exposed to media containing caged nanoparticles (200 $\mu \mathrm{g} / \mathrm{mL}$ ) and the culture flask was covered with a mask that only allowed light penetration in a $1 \mathrm{~mm}$ diameter area in its center (Fig. 6a). The flask was placed under an inverted microscope and left unperturbed for 10 minutes to avoid nanoparticles shifting prior to 1 minute of illumination. After illumination, the flask was carefully washed to remove unbound nanoparticles. Illumination with a UV lamp revealed that the particles were arranged in a tight pattern corresponding to the location of the window in the mask. The targeted cells were distributed in an area with a diameter of $\sim 6 \mathrm{~mm}$, probably due to nanoparticle diffusion after illumination or scattering of the light beam. Fluorescence microscopy (Figures $6 \mathrm{~b}$ and c) showed that more than $94 \%$ of the cells at the center of the light beam were targeted by the particles, i.e. were associated with at least one particle (Fig. 6b), while almost no cell targeting was seen in areas not exposed to light (Figure. 6c).

In conclusion, we report what is to our knowledge the first example of a targeting system capable of binding nanoparticles to cells selectively upon illumination. In contrast to other reports where nanoparticles have been triggered to produce a single drug release event by light9, 11,12 our approach results in the deposition of a sustained release system at the desired site. Another important point is that this system allows tissue targeting without specific markers (since the receptor for the ligand used in these experiments is ubiquitous throughout the body), provided the tissue can be illuminated. Furthermore, this approach could be used with specific ligands as well, perhaps further enhancing specificity. The potential applicability of caging to a spectrum of potential ligands is seen in the fact that it has been used to inactivate a wide range of biomolecules including peptides ${ }^{20}$, enzymes 21 , nucleotides 22 , mRNA 23 and DNA ${ }^{23}$.

The wavelengths at which DMNB can be made to un-cage (350-400 nm) limits this particular application of this technology to areas of the body that can be illuminated directly, including such important sites as the back of the eye (a notoriously difficult area for drug delivery systems to reach). However, the use of lasers and minimally invasive fiber-optic tools, and the development of new caging groups that respond to wavelengths with better tissue penetration such as near infrared, may make direct targeting of deep tissues possible. In vivo work will require the use of nanoparticles with direct applicability in drug delivery, such as liposomes and biodegradable polymeric nanospheres. Other modifications may also be necessary, such as surface optimization to minimize uptake by the reticuloendothelial system, e.g. by PEGylation.

\section{Experimental section}

\section{Assessment of targeter un-caging potential}

HPLC assays were performed on an HP 1100 HPLC system delivering $0.2 \mathrm{ml} / \mathrm{min}$. Samples $(1 \mathrm{mg} / \mathrm{ml})$ in $50-\mu \mathrm{L}$ volume were injected onto XDB-C18 column (Agilent, Eclipse). Pump A delivered 100\% $\mathrm{H} 2 \mathrm{O} / 0.05 \%$ TFA and pump B delivered 80\% acetonitrile/20\% H2O/0.043\% 
TFA. The components were separated by a linear gradient over $50 \mathrm{~min}$ from 5 to $100 \%$ buffer B. Peptides were detected at $210 \mathrm{~nm}$.

\section{Synthesis of the caged particles}

Ten milligrams of fluorescent polystyrene carboxylated nanoparticle suspension $(328 \pm 2 \mathrm{~nm}$, Merck Chimie S.A.S, Pithiviers, France) were incubated with $100 \mathrm{mg}$ of 1-(3dimethylaminopropyl)-3-ethylcarbodimide hydrochloride (EDC, Sigma) and $200 \mathrm{mg}$ of sulfoN-hydroxysuccinimide (NHS, Sigma) for 2.5 hours at room temperature with stirring. The resulting NHS-activated particles were covalently linked to $5 \mathrm{mg}$-GGGGY(DMNB)IGSR$\mathrm{NH}_{2}$ peptide (purity $>96 \%$ by HPLC, custom synthesized by Peptech Corp. Burlington, MA) overnight at room temperature with gentle stirring. The C-terminally amidated peptide GGGGYIGSR- $\mathrm{NH}_{2}$ was chosen in order to maximize the interaction with integrin $\beta 1^{16}$. GGGGYIGSR-NH $\mathrm{N}_{2}$ and the peptide $\mathrm{NH}_{2}$-GGGGFHPDYRVI-NH ${ }_{2}$ (GenScript Corp. Piscataway, NJ) which is not known to be an adhering peptide, were conjugated in a similar fashion and served as control targeters. The nanoparticles had $445 \mu \mathrm{eq} / \mathrm{g}$ carboxylic groups and introduction of the targeter in excess theoretically lead to the conjugation of $\sim 5000$ targeter molecules on each particle.

\section{Fourier transform IR (FTIR)}

Nanoparticle suspensions ( $200 \mu \mathrm{g} / \mathrm{mL}$ ) were illuminated for 0,1 and 5 seconds by a UV lamp at $365 \mathrm{~nm}$ (Entela, Upland, CA) in a 6-well plate. The suspension was collected and centrifuged and the supernatant medium was discarded. The isolated nanoparticles were then lyophilized for 24 hours and their spectra were determined by FTIR spectroscopy (Bruker Alpha-E, Billerica MA).

\section{Cell isolation}

Animals were cared for in compliance with protocols approved by the Massachusetts Institute of Technology Committee on Animal Care

Mesenchymal stem cells were isolated as described ${ }^{24}$. Briefly, the femur and tibia of 2-3month-old Sprague-Dawley rats (Charles River, Wilmington, MA) were aseptically excised. Bone marrow plugs were extracted from the bones by flushing the bone marrow cavity with culture medium. After a homogenous cell suspension was achieved, the cells were centrifuged (600 g, 5 minutes), resuspended in Dulbecco's Modified Eagle's Medium (DMEM) and plated on culture flasks. Three days later the media was replaced and adherent cells were considered MSCs. Second-passage BM-MSCs were used in all experiments.

\section{Cell culture and Cellular Binding}

HUVECs (Lonza Walkersville, Inc. Walkersville, MD), and MSCs were grown in 8-chamber slides in EGM-2 (Lonza) and DMEM (Invitrogen, Carlsbad, CA) media respectively. DMEM was supplemented with 100 units $/ \mathrm{mL}$ aqueous penicillin, $100 \mathrm{~g} / \mathrm{mL}$ streptomycin, and $10 \%$ fetal bovine serum. The cells were grown at concentrations to allow 90\% (HUVECs) and $\sim 70 \%$ (MSCs) confluence. On the day of experimentation, cells were washed with pre-warmed PBS then incubated in pre-warmed media containing $20 \mu \mathrm{g} / \mathrm{mL}$ of caged nanoparticles. The cultures were illuminated for 1 minute, shaken, incubated for 30 minutes at $37^{\circ} \mathrm{C}$, washed with PBS three times, stained with $\beta$-actin antibody (Sigma, St Louis, MO) and visualized by fluorescent microscopy. The number of targeted cells was quantified by fluorescent microscopy at $20 \times$ magnification and divided by the total cell number. All measurements $(n \geq 3)$ were averaged from at least 3 consecutive images within every well. 
For qualitative assessment of caged-nanoparticle targeting (Figures 5A and 6A) we added to the cell cultures media containing $200 \mu \mathrm{g} / \mathrm{mL}$ caged nanoparticles and the culture dishes/flasks were illuminated or not (UV lamp or $340 \mathrm{~nm}$ by inverted Zeiss microscope, Axiovert 200M for qualitatively targeting assessment and spatial targeting, respectively) for 1 minute before carefully washed, visualized by UV light transilluminator (TFX-35M, Life Technologies, Paisley, UK) and the images were photo-documented (Kodak digital science electrophoresis documentation and analysis system 120).

\section{Immunofluorescence staining}

Immunofluorescence stainings were performed as described ${ }^{25}$. Briefly, the samples were fixed and permeabilized in cold methanol, then blocked for 1 hour at room temperature in DMEMbased buffer containing 5\% FBS. After three buffer washes, the samples were incubated for 1 hour with 1:500 anti- $\beta$ actin (FITC-conjugated, Sigma) or 1:50 $\beta 1$ integrin (R\&D Systems, Minneapolis, MN) antibodies. After incubation, the samples that were stained with antibody against $\beta 1$ integrin were washed and incubated for additional 1 hour with goat anti-mouse Alexa 488-conjugated antibodies (1:150). For nuclear detection, the cells were incubated for 3 minutes with Hoechst 33258 (Sigma) and washed. Imaging was performed with an inverted Zeiss fluorescence microscope model Axiovert 200M and analysis was performed using AxioVision 4.5.

\section{Statistical analysis}

Data from cell targeting are presented as means \pm s.e.m. Differences between groups were assessed with a Student's $t$ test. All analyses were performed using GraphPad Prism version 5.00 for Windows (GraphPad Software, San Diego, CA). $p<0.05$ was considered statistically significant.

\section{Supplementary Material}

Refer to Web version on PubMed Central for supplementary material.

\section{Acknowledgments}

This research was funded by NIH Grant GM073626 to D.S.K. T.D. acknowledges a Postdoctoral Fellowship from the American Heart Association. M.R.B. thanks the Helen Hay Whitney Foundation for a Postdoctoral Fellowship. We would like to thank Natalia Schiller for technical assistance with the HPLC and Gadi Sarfati for helpful discussions.

\section{References}

1. Little S, Kohane D. Journal of material chemistry 2008;18:832-841.

2. Dvorak HF, Nagy JA, Dvorak AM. Cancer Cells 1991;3(3):77-85. [PubMed: 1711364]

3. Peer D, Karp JM, Hong S, Farokhzad OC, Margalit R, Langer R. Nature Nanotechnology 2007;2(12): 751-60.

4. Duncan R. Nat Rev Drug Discov 2003;2(5):347-60. [PubMed: 12750738]

5. Mallidi S, Larson T, Tam J, Joshi PP, Karpiouk A, Sokolov K, Emelianov S. Nano Letters 2009;9(8): 2825-31. [PubMed: 19572747]

6. Bagalkot V, Zhang L, Levy-Nissenbaum E, Jon S, Kantoff PW, Langer R, Farokhzad OC. Nano Lett 2007;7(10):3065-70. [PubMed: 17854227]

7. Farokhzad OC, Cheng J, Teply BA, Sherifi I, Jon S, Kantoff PW, Richie JP, Langer R. Proc Natl Acad Sci U S A 2006;103(16):6315-20. [PubMed: 16606824]

8. von Mehren M, Adams GP, Weiner LM. Annu Rev Med 2003;54:343-69. [PubMed: 12525678]

9. Bisby RH, Mead C, Morgan CG. FEBS Lett 1999;463(12):165-8. [PubMed: 10601660]

10. Manyak MJ, Russo A, Smith PD, Glatstein E. J Clin Oncol 1988;6(2):380-91. [PubMed: 2963095] 
11. Volodkin DV, Skirtach AG, Mohwald H. Angew Chem Int Ed Engl 2009;48(10):1807-9. [PubMed: 19173270]

12. Wu G, Mikhailovsky A, Khant HA, Fu C, Chiu W, Zasadzinski JA. J Am Chem Soc 2008;130(26): 8175-7. [PubMed: 18543914]

13. Ellis-Davies GC. Nat Methods 2007;4(8):619-28. [PubMed: 17664946]

14. Wang YG, Samarel AM, Lipsius SL. J Physiol 2000;526(Pt 1):57-68. [PubMed: 10878099]

15. Maeda T, Titani K, Sekiguchi K. J Biochem 1994;115(2):182-9. [PubMed: 8206865]

16. Graf J, Ogle RC, Robey FA, Sasaki M, Martin GR, Yamada Y, Kleinman HK. Biochemistry 1987;26 (22):6896-900. [PubMed: 2962631]

17. Rhee H, Lee JS, Lee J, Joo C, Han H, Cho M. J Phys Chem B 2008;112(7):2128-35. [PubMed: 18211054]

18. Karpen JW, Zimmerman AL, Stryer L, Baylor DA. Proc Natl Acad Sci U S A 1988;85(4):1287-91. [PubMed: 2448798]

19. Tsur-Gang O, Ruvinov E, Landa N, Holbova R, Feinberg MS, Leor J, Cohen S. Biomaterials 2009;30 (2):189-95. [PubMed: 18849071]

20. Walker JW, Gilbert SH, Drummond RM, Yamada M, Sreekumar R, Carraway RE, Ikebe M, Fay FS. Proc Natl Acad Sci U S A 1998;95(4):1568-73. [PubMed: 9465056]

21. Ghosh M, Song X, Mouneimne G, Sidani M, Lawrence DS, Condeelis JS. Science 2004;304(5671): 743-6. [PubMed: 15118165]

22. Kaplan JH, Forbush B 3rd, Hoffman JF. Biochemistry 1978;17(10):1929-35. [PubMed: 148906]

23. Ando H, Furuta T, Tsien RY, Okamoto H. Nat Genet 2001;28(4):317-25. [PubMed: 11479592]

24. Barbash IM, Chouraqui P, Baron J, Feinberg MS, Etzion S, Tessone A, Miller L, Guetta E, Zipori D, Kedes LH, Kloner RA, Leor J. Circulation 2003;108(7):863-8. [PubMed: 12900340]

25. Dvir T, Levy O, Shachar M, Granot Y, Cohen S. Tissue Eng 2007;13(9):2185-93. [PubMed: 17518740] 
Figure 1. and the targeter becomes active.
Nanparticle with peptide ligand

Peptide ligand

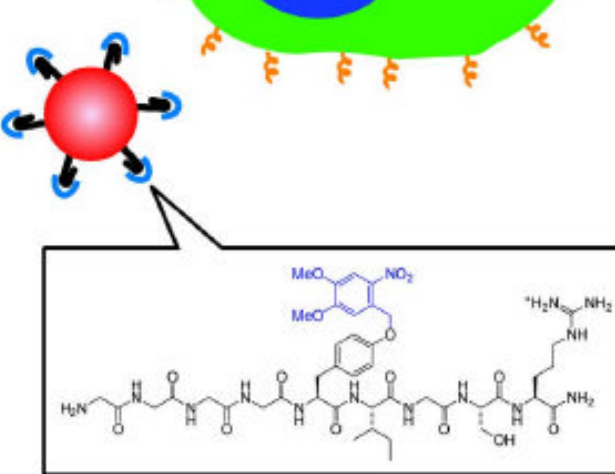

-GGGGY(DMNB)IGSR-NH 2
Caged

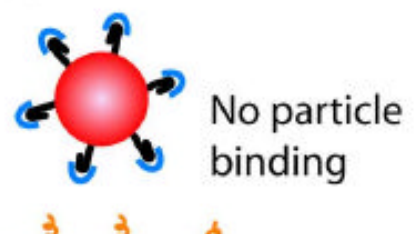

Uncaged

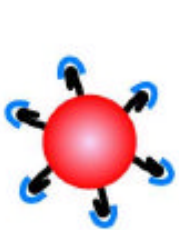

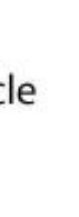

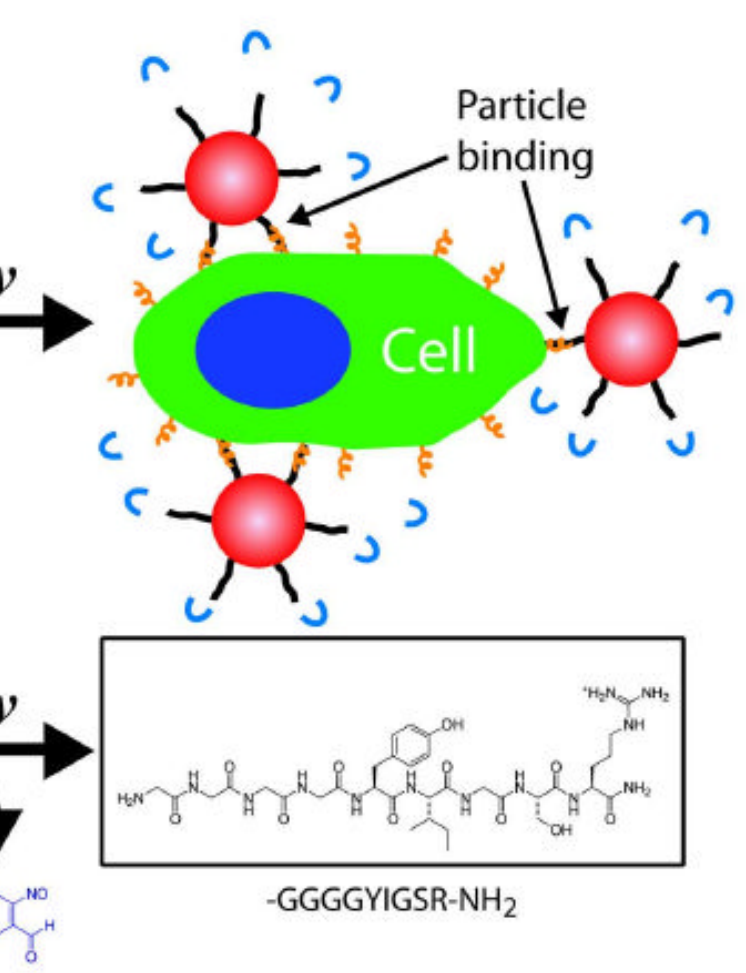

The photo-targeted nanoparticle concept. A non-specific ligand on the surface of the nanoparticles is caged, rendering it non-functional. Upon illumination, the caging group is released, the ligand is activated and the nanoparticle can bind to the illuminated tissue. The lower portion of the figure shows the chemistry of the targeting moiety as it relates to the events schematized above. The GGGGYIGSR-NH $\mathrm{NH}_{2}$ peptide is caged on tyrosine with a 4,5dimethoxy-2-nitrobenzyl group (DMNB, Blue). After illumination the caging group is released 


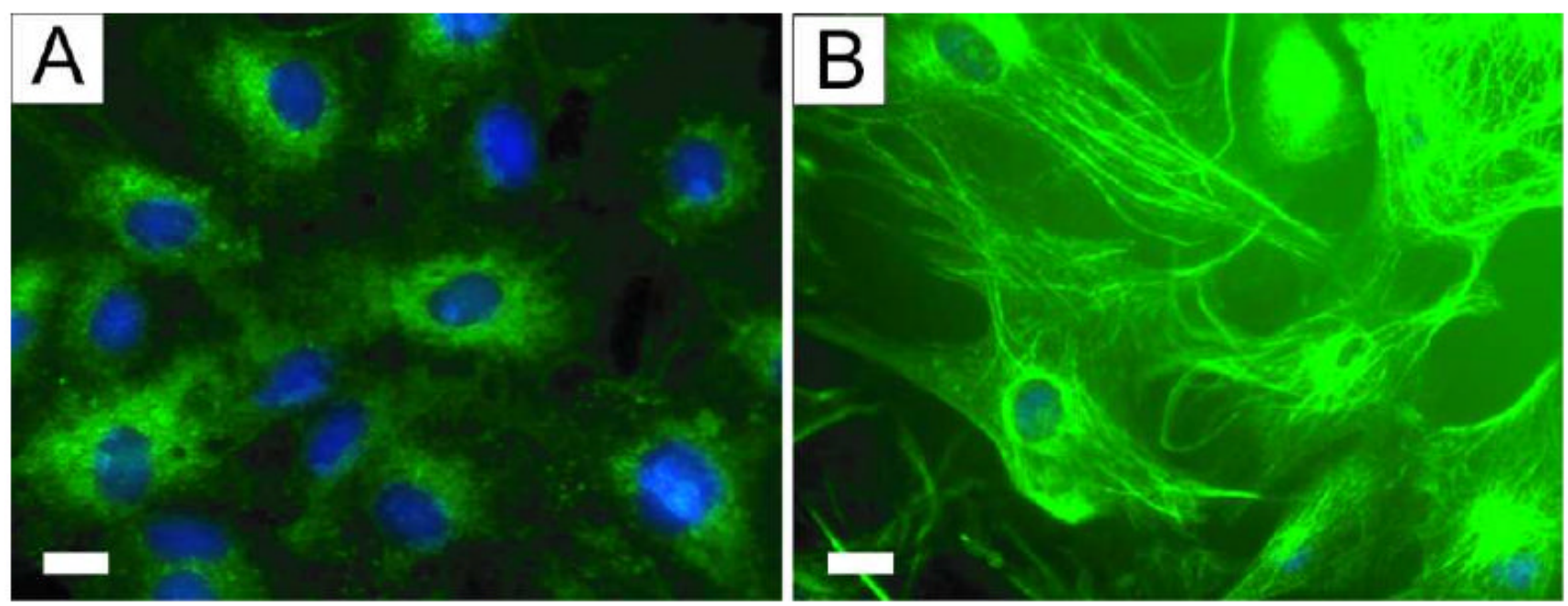

Figure 2.

Expression of integrin $\beta 1$ (green) on endothelial (A) and mesenchymal stem (B) cells. Cell nuclei are stained in blue. $\mathrm{Bar}=10 \mu \mathrm{m}$. 
A
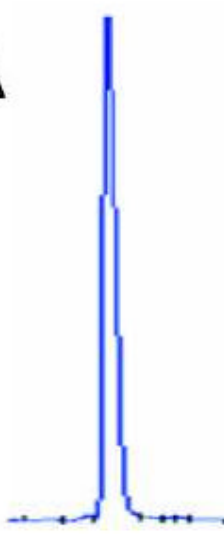

B
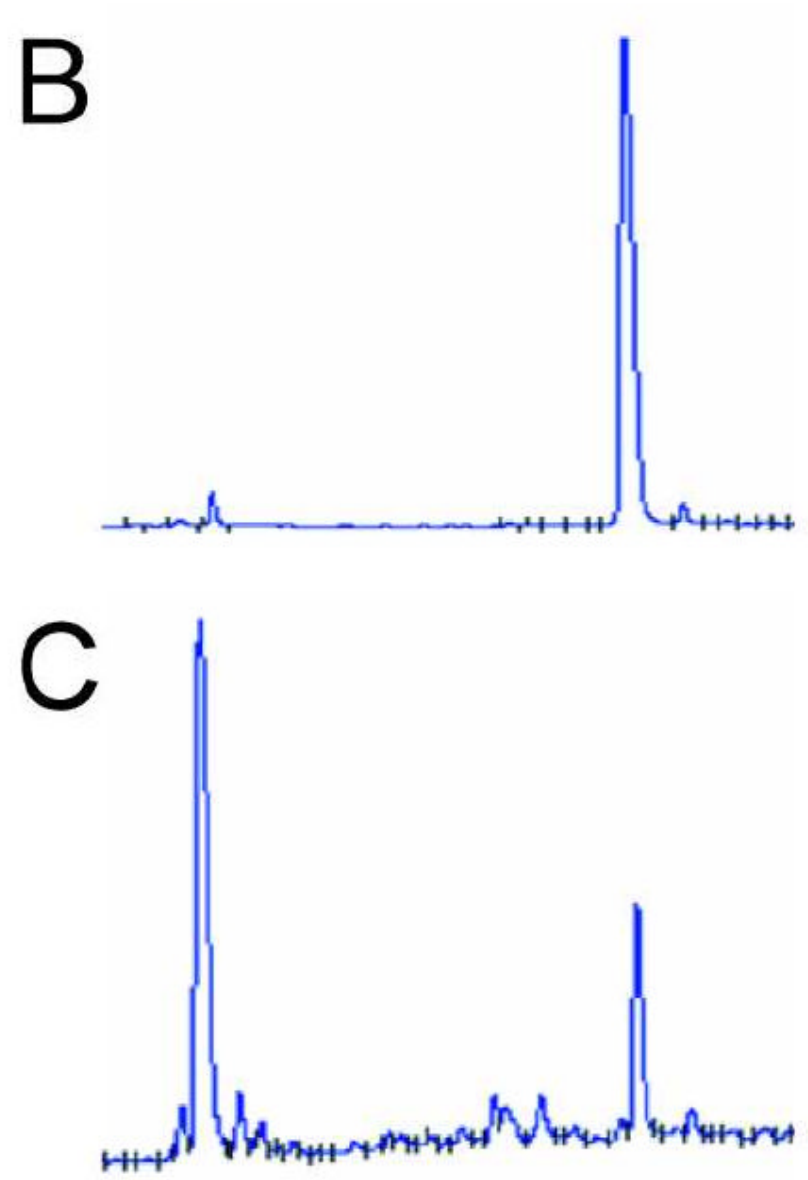

Figure 3.

HPLC chromatogram of (A) non-caged peptide, (B) non-illuminated caged peptide, and (C) caged peptide after 1 minute illumination. 

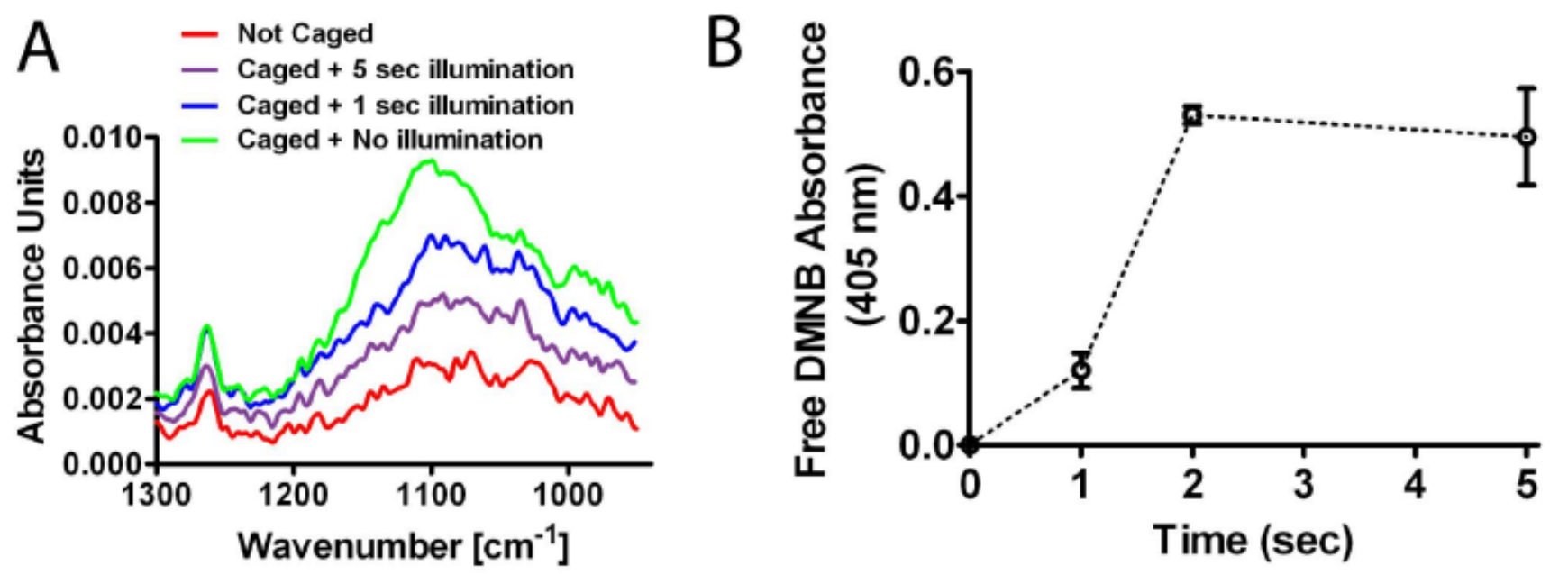

Figure 4.

Release of the caging group from the nanoparticles. (A) The disappearance of the ether bond on the targeter as assessed by FTIR. (B) Release of free DMNB caging group from nanoparticles modified with Y(DMNB)IGSR. 


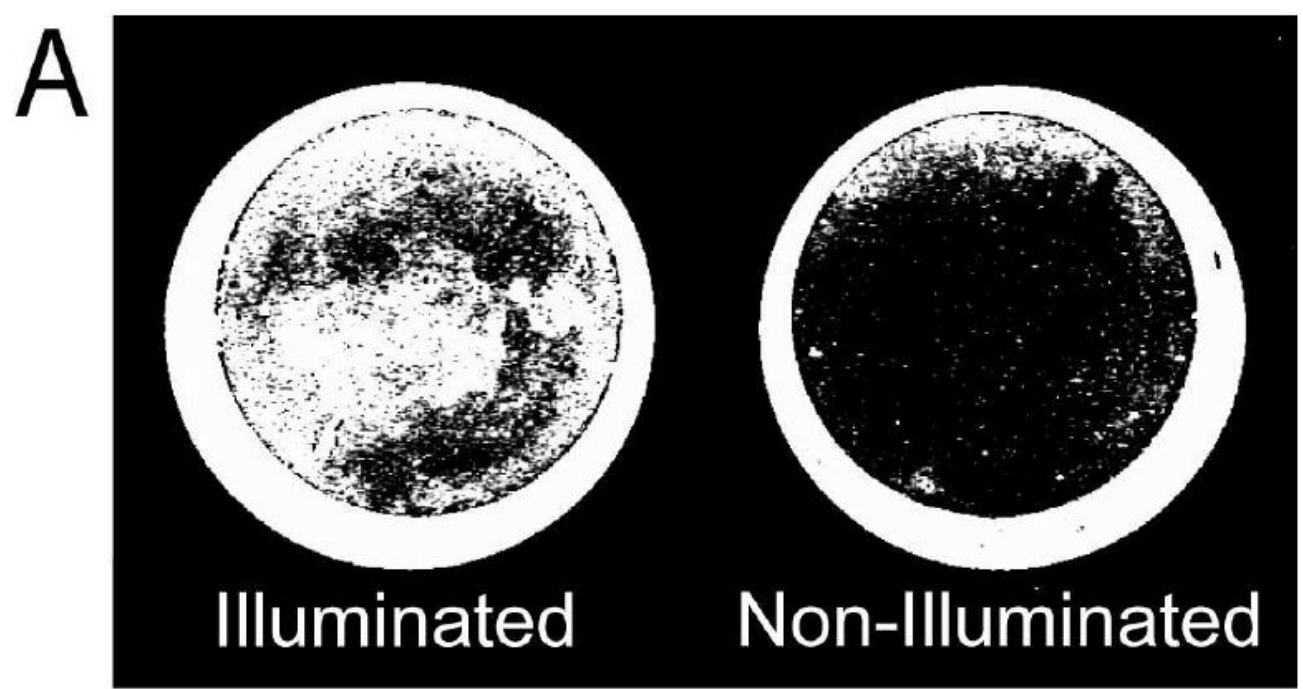

B
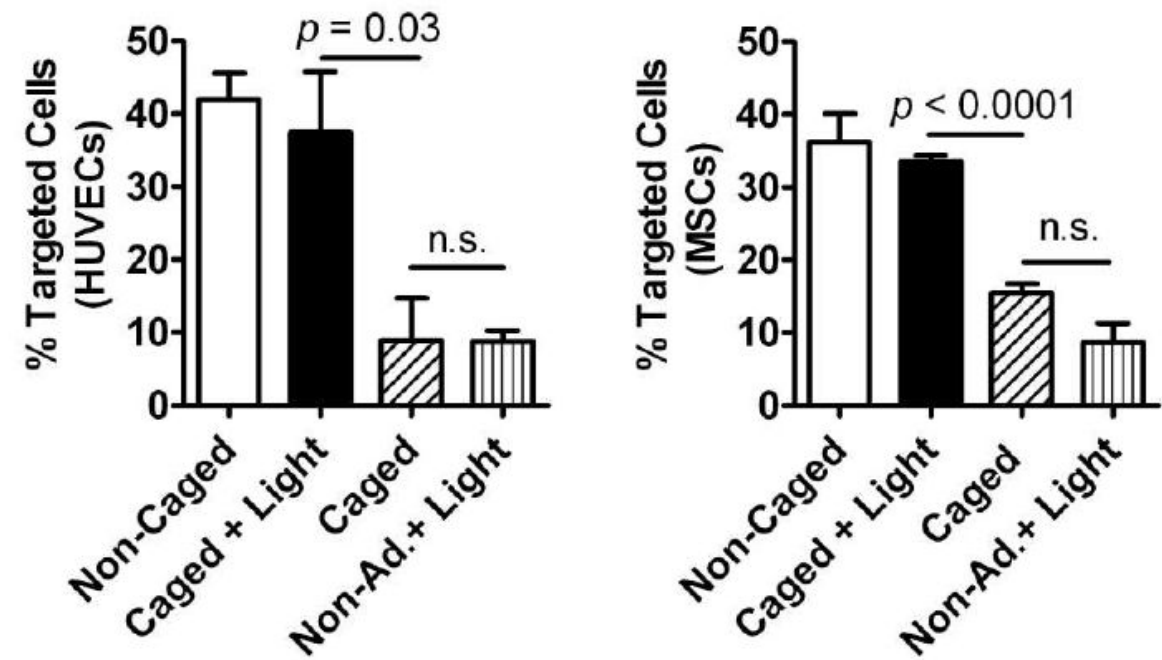

Figure 5.

Nanoparticle targeting. (A) Attachment of nanoparticles with caged YIGSR peptide to HUVECs in illuminated and non-illuminated cultures. The particles appear white. (B) Percentage of HUVECs and MSCs targeted by nanoparticles. The nanoparticles were labeled according the type of surface ligand: "Non-caged": YIGSR, "Caged": Y(DMNB)IGSR, "Nonad" the non-adhering peptide (FHPDYRVI). 

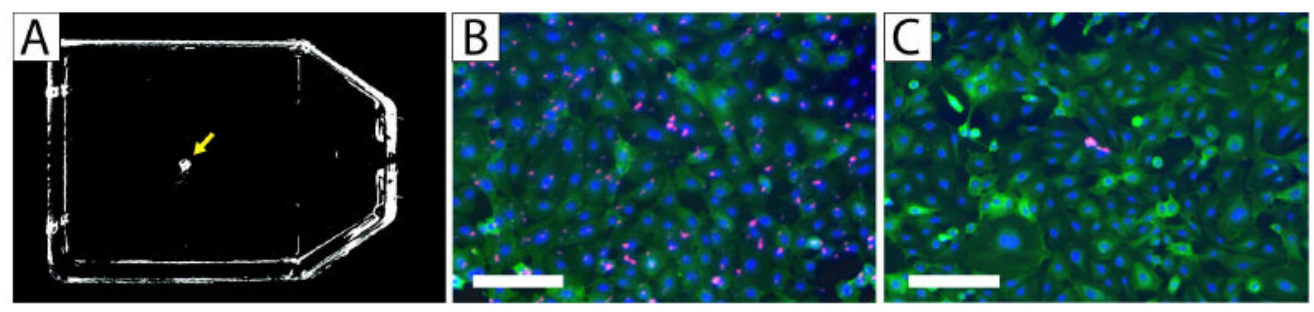

Figure 6.

Targeting of HUVECs. (A) Macroscopic view under UV illumination of fluorescent nanoparticles adhering specifically to cells in a small area that had been illuminated at $340 \mathrm{~nm}$ for 1 minute (arrow). (B) and (C) Microscopic views of the cells in the illuminated area (B) or located $1 \mathrm{~cm}$ away (C). Cell cytoplasm was stained with $\beta$ actin antibody (green), nuclei stained by Hoechst (blue) and the nanoparticles appear red. Bar $=100 \mu \mathrm{m}$. 